\title{
Is Public Sociology Possible? Reconstruction of Sociology through Communicative Action
}

\author{
Assoc. prof. Alfred BULAI, PhD \\ Faculty of Political Science \\ National University of Political Studies \\ and Public Administration, Bucharest, Romania \\ E-mail: alfbulai@yahoo.com
}

\begin{abstract}
This article analyzes the model of public sociology proposed by Michael Burawoy, focusing on the possibility of building a public sociology. I will demonstrate that the Burawoy model has no sufficient theoretical consistency and needs to redefine its basic concepts. The public sociology paradigm has implications that go beyond the dialogue of the sociologist with its public. If we develop the Habermas model of Communicative Action in its details, we discover that public sociology could be possible, yet implies major changes in the way sociology currently works, which means a redefinition of some fundamental paradigms of our society. Among these, two are crucial: they concern the educational system and the market of knowledge. To do public sociology accepting the model of communicative action, it is necessary to transform the basis of our educational system and the main principles of the market of knowledge.
\end{abstract}

Keywords: Communicative action; Social communication; Emancipation; Public; power; Public social data; Illegitimate inequalities; Public policies in education. 


\section{Argument}

In 2004, the American Sociological Association (ASA) President, Michael Burawoy, proposed a major challenge to the participants to the annual congress of the association. That is, the idea of redefinition and - implicitly - the reconstruction of sociology within a public dimension, through a rediscovering of sociology's public fundament. The emancipative vocation of sociology, which should protect civil society and the social dimension of "market tyranny and state despotism," is, in Burawoy's view, the ultimate and most important goal of sociology in this century (Burawoy 2005).

\section{Characteristics of the theoretical model of public sociology}

Burawoy proposes a model of social functioning of sociology. He starts from an indisputable premise: that sociology has and must have different publics. Even we, as an academic community, could be regarded as a type of public, and our students could be another type, one that, Burawoy says, should be helped to discover its role in society. Yet, in like manner, we could think as a public of all those who require a sociologist's services. The essential mission of sociology has always been lending support, and, through dialogue with the public, emancipating it against dominant structures of state or market. This means implicitly to give to the public or to help it gain power (Burawoy 2005, pp. 17-19).

To analyze how public sociology is functioning within this theoretical model, we need to analyze its central features. Thus, public sociology - explicitly or tacitly - admits few key theses:

1. Sociology is produced in heterogeneous, multidisciplinary scientific communities, focused on four possible roles of the sociologist. These roles define the four types of sociology: public, professional, critical, and policy-centered. Patterson (2007), who rejects this model as inappropriate, suggests in turn a typology - which is in fact similar -, drawing a distinction between discursive, active, civic, and professional sociology. In reality, we do not deal with different types of sociology, but with functions that sociology, regardless of its disciplinary field, might have.

2. Sociology requires engagement and a critical, reflexive attitude towards the objective of emancipating individuals against the excessive power of the state and market, but probably against anyone who could threaten civil society. The watchdog role of civil society is implied here, including the idea that sociology's position would always be towards the left (Piven 2007).

3. Sociology has an internal democratic value, in comparison to other sciences, e.g. economics or political science, which can serve the interests of state or market. Sociology has a tacit enlightenment role, different from others sciences: to emancipate the public, and to reform and democratize society. 
4. It tacitly admits the idea that society needs sociology, an organic need based on a historical mission of this discipline. It is implicitly accepted that the only viable form of sociology is one that accepts and generates social change towards attaining freedom and promoting general human values. Is assumed the thesis that within public space, the sociologist's voice is important because he or she has the knowledge necessary in order to help groups and communities; moreover, he or she has inoculated referential values that are necessary in society.

5. Finally, public sociology assumes as a postulate that we live in a society with inequalities and disparities of power that are illegitimate, and we must correct them with the help of sociology.

Assuming that we admit all these five referential theses of the model, including the 'messianic' role of sociology, we then raise a simple question: how could this emancipator function of sociology be translated into practice? In our opinion, here is the first major weakness of the proposed model. Whereas Burawoy defines as referential the active/civic dimension of sociology and the necessity of interactive dialogue with different publics, he admits that the mere publication of a book for a wide audience represents a type of public sociology, which he regarded as traditional. Burawoy also admits that this type of public sociology existed throughout the history of the discipline. This option suggests that public sociology could be reduced to a mere discursive style, one capable of being perceived by large audiences. This kind of reduction to a simple matter of discursive style raises a major question about the theoretical viability of public sociology. It is obvious that an attractive style of communication is always useful, especially when addressing a lay public. Yet, the accessible and attractive writing style may characterize any scientific discipline, and it would make it difficult to argue why the case of sociology is a special one.

Likewise, many other theses of the model raise questions on the same grounds. There are different kinds of public for any science. All science concerns society, because absolutely all strains of science have an instrumental function that operates in the social sphere. Moreover, any science contributes through this instrumental dimension towards generating social change. Then, why is it that sociology differs from other sciences in what concerns its public dimension? To answer this question, it is still needed to make some comments regarding the possibility to define public sociology.

\section{Which are the main characteristics of public sociology?}

Public sociology should define something more complex than a dialog with the public, or a particular political position that one sociologist can have on the grounds that he/she is employed by one side or another of the barricade. It should 
also mean more than awareness or recognition of the moral implications that scientific knowledge can entail, as Wallerstein (2007) suggested and, especially, it cannot be reduced to an attractive style of scientific discourse.

Based on the work of some renowned sociologists committed to the field, we try to capture the defining elements of public sociology. I will examine these theses to discover whether they can be admitted as sufficient definitions of public sociology.

Public sociology refers to the work of sociologists as having one or more publics. We showed that this statement is common sense evidence, which leads to a simple truism, as long as all sciences have at least one public and communicate with them. Obviously, the entire population represents a public for any sciences, because of the compulsory dimension of education. Thus, one could discuss about public mathematics, public chemistry, public ecology, and so on. In these circumstances, the "public sociology" phrase would be a redundancy.

Public sociology refers to the fact that the sociologist can influence social change, through dialogue and his/her presence in the public sphere. Public space is always heterogeneous. The public receives information from many sources, and is always part of a multiple dialogue (Habermas 1984). Moreover, sociologists communicate on the same topics as many others actors, such as journalists, politicians, economists, specialists from various scientific or technical fields, as well as various other cultural elites. The emancipative force of the sociologist, given by his/her public appearances, is much lower than it is implied by Burawoy's approach. Moreover, the actors from these processes of communication are not necessarily proficient in the knowledge they offer, and that they have more than one value orientation. Messages they convey are inconsistent and cannot be otherwise. Social, political, or economic power, on the other hand, represented by the state or the market is part of this process of dialogue. Yet the power structures have their own public communicators. To be honest, in fact, most times, these professionals have more resources to access publics than sociologists.

What is more, the political activism of a sociologist and his/her participation to public dialogue is not a form of public sociology, because this involvement might represent nothing more than a type of political activism. There is certainly a public dimension to this type of commitment, but we cannot reduce public sociology to this aspect. Also, the risk of politicization, invoked by many authors, is a real one (Abbot 2007).

Public sociology refers to the fact that products of knowledge must go beyond the interests of clients or of any kind of organization or person that finances research. The sociologist, based on his/her system of values, should not compromise his/her scientific practice or his/her ethics by alien interests. That is the idea formulated by Patterson (2007). A sociologist can work for various political clients, Patterson says, but he/she should not taint the research results because 
of the relationship with beneficiaries. Besides, the sociologist can provide those results to a wider public than those strictly defined by his/her contract. That is an approach that involves more than the previous, but still does not mean anything other than a code of ethics of someone practicing this profession.

The public character of sociology means that sociological research can be used or has to be used to solve public issues. Of course, it is possible to use this definition, agreed upon by many authors. This public character, however, is provided only if the potential beneficiaries desire that. In the end, the intervention strategy is based on supplying information and social data to the public. But who makes the distinction between information and manipulation, or who provides assurance that the intervention will be beneficial to the public and not to those who finance research? The sociologist may assume a kind of responsibility, but in practice he/she is not involved in managing social change, and therefore has no possibility to intervene in the actual implementation of public policy.

Public sociology entails that the sociologist can address non-professional audiences through appropriate language, using an attractive style, to provide them with information and an understanding of a particular social problem. It is a purpose explicitly admitted by Burawoy. Righteously, he appreciates the great sociologists who adopted an attractive style in their works. Bellah and his colleagues, Riesman and Myrdal, were explicitly quoted by him. Also, DuBois, Adams, and other European sociologists are often offered as examples by other authors (Burawoy 2005, p. 7). But we can raise the same question as earlier, as the same situation applies to any science. What about James Frazer, Albert Einstein, Bertrand Russell, Sigmund Freud, Jacques Le Goff and many others is making them inferior? A huge number of scientists, in many scientific areas, have used a style aimed at large audiences in their public appearances and works. What is so special about sociologists?

From the author's point of view, any previous thesis can be a partial definition of public sociology, yet insufficient to understand its very nature. Public sociology can be defined theoretically, it can even be a professional or a research field and, moreover, it is necessary. Apparently, this position is contrary to all theses that were presented above. On the contrary, the author tries to demonstrate that public sociology must be seen as having a more complex status. It must be defined in a manner not reducible to a matter of style of speech or to a simplistic statement as the idea of the dialogue with a certain public.

\section{Why does sociology need to become public?}

The object of study of sociology, by comparison to other social sciences, is power and social change. Knowledge provided by the sociologist may be more or less efficient, but it always has an instrumental value for managing social change. The sociologist as an individual does not have the power to generate change. Knowl- 
edge is power, only in a figurative sense. Knowledge can help to make sense of reality, and when it concerns social life, it allows manipulations of social relations, including power relations. Knowledge provided by the sociologist, by any social scientists in fact, is capitalized by social structures with sufficient power to generate social dynamics. Certainly, groups or categories that are dominated, to the extent to which they have access to certain resources of power, can become active in their emancipation action, including on the basis of scientific knowledge.

By the very nature of its object of study, the sociologist, by comparison to other specialists, is closer to the possibility of intervening in the social dimension. This status provides expertise to sociologists. Through his/her competence, the knowledge that they can provide could be a factor used in managing power within society. Of course, some knowledge products provided by sociologists can regard disparities of power. Knowledge can be used to limit these disparities or towards their growth. Direct or indirect beneficiaries of this knowledge will generate such changes in the desired sense. In such situations, a sociologist could know or not how knowledge provided by them is used. If the sociologist agrees to participate as advisor to policy-makers in managing these processes of social change, they may have greater access to the mechanisms of using knowledge they lend. According to a personal equation of their values, the sociologist could want and accept such a role, or not.

The key element of public sociology, the author states, should not be the sociologist or sociology, but the public. The definition of public sociology should not start with what a sociologist ought to do or what sociology should be. The definition has to focus on the concept of 'public.'

In fact, the communicative action theory as a solution for understanding how dialogue could work, even as suggested by Burawoy, involves the idea of building mutual consensus between communicative actors in an inter-subjective understanding of goals and accepting that these are acceptable and reasonable (Habermas 1984). However, it is not very clear how this instance could be feasible. Do the public and the sociologist need to already have such an understanding of goals? Do they need to have a common cultural basis and a similar stock of knowledge? How could dialogue work without a common basis, and how could one build this it, if it does not exist? The concept of public used by Burawoy is only a partial solution. In fact, it leads us to a very static perspective of communication that, in fact, is very different to Habermas' view (Habermas 1984, 1987).

Burawoy's approach, unfortunately, reduces the public to mere examples, to the object of a possible dialogue of the sociologist. The public dimension of sociology requires a redefinition of the discipline in a social and institutional dimension, which should go beyond the emancipation that is tackled too ideologically. The theme of emancipation can only be a special case of the public functions of sociology (Wallerstein 2007). 
I believe that the public should remove itself from the tyranny of the state and market, but also from the tyranny of the sociologist who knows what is best for the public, for the state, or for the individual. If one wants to create science, and to admit that the idea of the public (in its modern sense) is itself a central value in the reporting of social life, public sociology should become a tool. Not a branch of sociology, but a way to define the scientific practice of sociologists. This means to initially define the rules and mechanisms for the public access to information and to products of social research. The access does not mean just removing some barriers, but the legal responsibility defined by public policy to provide information to the public and to allow the acquisition of conceptual tools, more generally, to allow skill-building to use analysis, interpretation, and management of information and social data by any kind of public. If one seeks consent regarding goals produced through communicative acts, one needs a certain level of knowledge and a certain level of cognitive competence to deal with social data (Habermas 1984).

Public sociology should start with defining the role that social knowledge should play in public space. The access of any public to social knowledge and to its products represents the essence of public sociology, even if, in fact, one conceives sociology in the same terms as all social sciences. It is not about emancipation; one cannot speak of a certain action model that the sociologist should advance. The sociologist cannot be a demiurge without, in turn, being a despot. They have no way of knowing what is good or not for a public or another. The true emancipation resides precisely in the sociologist's nonintervention. The tyranny of the state cannot be replaced by the tyranny of science over the public. The public must find its own political or civic horizon by themselves, and not in dialogue (tacitly presumed as persuasive) with the sociologist.

Knowledge has a referential value for any society, which needs no further validation. One can consider this thesis as a postulate. The entire history of humanity was based on permanent capitalization of knowledge. Sociology, like any other social science, provides knowledge. This knowledge, through its instrumental function, is valued in society. Public sociology can maximize this process, make it more efficient, and it can eminently democratize the functioning of knowledge in society.

From the above, two essential components emerge in regard to the public nature of sociology:

- On the one hand, we speak about the public definition of sociology, which would mean a redefinition of the role of sociology, as science that provides knowledge, in society. The public definition covers public access to information and to the intellectual products of the social scientists that have to be open for retrieval to all publics. Access, in turn, requires two components: one regarding the regulations pertaining to the direct access to information and social data, and a second, more important, which regards the training of 
the public, to use and manage the social data and information. It is not only about access, but it is also necessary to prepare the public to operate with data and social information. Thus, it entails education and sociological training, in order to develop skills for operating with data, information, sociological concepts, and theoretical models. This, however, does not concern only certain elites, but the general public.

Free access also means that at least part of the information and social data have to be defined as public goods, which should evade the "tyranny" of the market. At least the basic social research results should have society as its beneficiary. These data should not be the object of private property, which is able to limit public access. This is not an easy task, given that contemporary science - and sociology is no exception - operates primarily based on private funding and on sets of rules defined by the "despotic" state bureaucracy or by the "tyrannical" market organizations. It is indisputable that some data or social information may have a private or commercial character like those from economic space. However, at least some social data, regardless of who pays for it, should be defined as public goods, if only for the public involved in the social investigations. For example, if a company conducts a sociological study on its employees for raising their work efficiency, the results should be public to all members of the organization, whether or not they took part in the research, because it is data about their community.

- The second component regards the presence of a particular language for the presentation of scientific data aimed at large audiences, composed of nonprofessionals. Touraine, Burawoy, and Wallerstein (2007) point out that this actually happens in many societies, in different ways, and with notable differences (Touraine 2007). Through language, one does not only refer to a certain style of written discourse, but also to the use of different kinds of language, such as visual, or those offered by the internet.

The success of public sociology does not only mean that the sociologist is engaged in public debate. Also, the mere fact that a sociologist is a government expert who is fair, does not compromise their principles, and helps communities, groups, or other social structures, does not necessarily make them a public sociologist; not because the sociologist should not engage with the public, but because the public should be able to engage in dialogue with the sociologist or with any other actor who is a provider of knowledge.

The public activism of the sociologist does not transform their knowledge into public sociology. The public character can exist only if one defines the public regime of social information, of the knowledge in society, and public policies, to establish the core role of social and human sciences in society. Access to knowledge and to public debates on social data is the essence of public sociology. In practice, 
this can only be achieved if sociology becomes a discipline taught in the elementary education system, if it opens primarily conceptually (at base level) to the public, if it is defined as mechanism of free access to social data (at least partially defined as public goods), if one defines political and legal rights of publics to free access to scientific information concerning them and society in general.

But how is it possible to make public sociology? Of course, the communication component is achievable relatively easily, because sociologists have been expressing themselves in extra-professional spaces. Even today, many sociologists have an important role as opinion leaders by their activity in the media, public debate, or by publishing their works for the general public. As Touraine (2007) suggests, this is an important phenomenon in Europe. In this respect, about the necessity for a sociologist to get out and communicate to the public, the author's position is not different from Burawoy's.

At the educational policy level of access to social knowledge, the discussion is more complicated. Sociology is taught in school minimally, and sometimes not at all. In some countries, sociology is not taught in high school, only as basic introduction, usually together with information from others social sciences. Most often, there are neither programs dedicated to the study of sociology in compulsory education, nor for most other social sciences. Access to information and social data is defined by the market, which is highly restrictive and certainly based on a specific structure of existing inequalities in society. On the other hand, even if there are free or relatively free sources of information, there are important parts of them that are not accessible to the public. Access to information and data about public is regulated rather from a deontological standpoint, at a minimum, especially related to matters that could adversely affect the community studied.

It is necessary to define the access to data and social information more generally, to reach our goal of building a public dimension of sociology. The study of sociology should be considered a matter of the functional literacy of citizens in contemporary societies. Also, social data should be regarded of public interest, and would have to undergo a free access. Finally, there should be promoted laws, rules, and standards that ensure that social knowledge cannot be the object of public or private monopoly.

These are some suggestions that could rather demonstrate that this process is hardly feasible, as free access to scientific information raises structural problems. It is defined only in partial terms, and no national, regional, or international association of sociology advocates or requires something towards this end. Nowadays, the public character of social information is provided only by free sources, centered on articles and books, which is relatively less. Of course, one can argue that on the social information market anybody can have access to the published works of sociologists, which can be found in libraries, if for whatever reason one cannot 
purchase it. However, access to scientific articles is limited by the market, even for libraries, accessible only to a very small part of population.

For the purpose of fairness, one should still inquire why sociology is in a different situation from other sciences. Apparently, there is an identical situation in other sciences, where free access is also limited by the market. However, the situation is different in sociology precisely because social information about individuals as social actors is about themselves, because in social sciences inquirers are always part of the study object. Information and data about social actors may be relevant for them in a manner quite different from the information about quasars. If one has information regarding structural rate differences between whites and other races in American prisons, by comparison to corresponding rates of the population that is not in prison, this is very relevant information if one is from the U.S., regardless of the race to which ones belongs. In regards to ethnic differences, the situation is similar for any other country. This type of social information, default the access to it, is not similar to that from stellar physics for example. If in physics one finds that other models of stars, such as red giants, which are very different from our sun, even if our sun is very important for us, these two types of information are radically different.

Although sociological knowledge products are usually more important for social actors compared to those provided by other sciences, such as those of nature, they are present, usually in a much lesser extent in general education and compulsory curricula. The starting point of public sociology should be, in the author's opinion, right here. Perhaps the central element in defining public sociology should involve redefining the paradigm of education as a priority in contemporary society. The central goal of education should be to prepare people not so much for work, but for living in a societal framework.

It is an honor for a sociologist to study the social conflict and the discrimination in the ethnic and racial relationships, inequalities, or to analyze various social problems. The sociologist exposing themselves by presenting their research data could be praised. The sociologist who aims to convey scientific data even to the public that are subject to discrimination could be appreciated. Likewise, their engaged attitude and effort to emancipate the public could be appreciated. To a certain limit, all these things can be accepted as part of public sociology. Yet if public sociology stops here, then it simply becomes a delusion, a hyperbolical appreciation of the sociologist in relation to other thinkers, a simple political definition for the way in which knowledge is used within society.

All these elements are nothing else but the inception for the process of construction of sociology's public dimension. Certainly, public sociology must be based on Communicative Action. Yet this in fact requires, in the spirit of Habermas' theory, more than a simple dialogue; it is necessary to create a new paradigm of social 
knowledge, as well as to build a social function for sociology, and to reshape our educational paradigm. The public dimension of sociology consists precisely in its original meaning, in assuming a public dimension of knowledge, not reducible to a dialogue of the sociologist with one public or another.

\section{References}

1. Abbot, A. (2007). The Humanist Sociology, in Public Sociology, fifteen eminent sociologists debate politics $\mathcal{E}$ profession in the twenty-first century, University of California Press.

2. Agger, B. (2000). Public Sociology. From Social Facts to Literary Acts, Rowman \& Littlefield Publishers.

3. Burawoy, M. (2005). 2004 Presidential Address. For Public Sociology. American Sociological Review, vol. 70, no. 1.

4. Habermas, J. (1984). Theory of Communicative Action. Volume One: Reason and the Rationalization of Society, Beacon Press.

5. Habermas, J. (1987). Theory of Communicative Action, Volume Two: Lifeworld and System: A Critique of Functionalist Reason, Beacon Press.

6. McClung, A. L. (1976). Presidential Address: Sociology for Whom?. American Sociological Review, vol. 41, no. 6.

7. McClung, A. L. (1978). Sociology for Whom?, Oxford University Press.

8. McClung, A. L. (2011). Sociology for People, Pioneers of Public Sociology, Sloan Publishing.

9. Patterson, O. (2007). About Public Sociology, in Public Sociology, fifteen eminent sociologists debate politics \& profession in the twenty /first century, University of California Press.

10. Piven, F.F. (2007). From Public Sociology to Politicized Sociologist, in Public Sociology, fifteen eminent sociologists debate politics \& profession in the twenty /first century, University of California Press.

11. Touraine, A. (2007). Public Sociology and the End of History, in Public Sociology, fifteen eminent sociologists debate politics \& profession in the twenty /first century, University of California Press.

12. Wallerstein, I. (2007). The Sociologist and the Public Sphere, in Public Sociology, fifteen eminent sociologists debate politics \& profession in the twenty /first century, University of California Press. 